UDC 331.104

LBC 65.050

\title{
THE ACTIVITIES OF THE RUSSIAN TRIPARTITE COMMISSION AS A MACRO-ASPECT OF SOCIAL DIALOGUE FACILITATION
}

\author{
Kseniya A. Subkhangulova \\ Lomonosov Moscow State University, Moscow, Russian Federation
}

\begin{abstract}
This paper highlights the definition of the 'social dialogue' concept and the results of its study at the national level in Russia. The relevance of this research is determined by the need to harmonize social and labor relations as one of the main sources of increasing labour productivity and satisfaction of both workers and employers (with assistance of the government). This is important under the conditions of global labour market change - increase in flexibility and emergence of new labour forms. The paper presents an analysis of the Russian tripartite commission activities. The research materials include the data of the commission sessions' protocols for the last 8 years (from 2010 to 2017), as well as the data on violations following the results of the State Labour Inspection work in regions of the Russian Federation for 2013-2016, presented in reports of Federal Service for Labor and Employment. We single out the main questions that had been considered at meetings for the last 8 years and the frequency of their discussions. The research results show that categories and frequency of the questions considered at commission sessions do not necessarily have a direct link with the labour violations recorded by official services. At the same time, the number of labour violations on some questions is reduced due to the establishment of coherence among three parties that confirms the importance of social dialogue among all the participants. Besides, we have outlined the main problems in the work of the Russian tripartite commission on the basis of the studied protocols.
\end{abstract}

Key words: social dialogue, the Russian tripartite commission, violations, social and labour relations, workers' associations, employers' associations, social partners.

УДК 331.104

ББК 65.050

\section{ДЕЯТЕЛЬНОСТЬ РОССИЙСКОЙ ТРЕХСТОРОННЕЙ КОМИССИИ КАК МАКРОАСПЕКТ РАЗВИТИЯ СОЦИАЛЬНОГО ДИАЛОГА}

\author{
Ксения Альмировна Субхангулова \\ Московский государственный университет им. М.В. Ломоносова, г. Москва, Российская Федерация
}

\begin{abstract}
Аннотация. Статья посвящена определению понятия «социальный диалог» и результатам его исследования на национальном уровне в российской действительности. Актуальность данного исследования обусловлена необходимостью гармонизации социально-трудовых отношений как одного из основных источников повышения производительности труда и удовлетворения интересов стороны работников и стороны работодателей (при поддержке государственной власти), что немаловажно в условиях изменения глобального рынка труда: повышения гибкости и появления новых форм трудовой деятельности. В статье представлен анализ деятельности Российской трехсторонней комиссии, в качестве материалов для исследования были рассмотрены данные протоколов заседаний Комиссии за последние 8 лет: с 2010 до 2017 г., а также сведения о нарушениях по итогам работы государственных инспекций труда в субъектах Российской Федерации за 2013-2016 гг., представленные в отчетах Федеральной службы по труду и занятости. Автором были выделены основные вопросы, которые рассматривались на заседаниях за 8 лет и частота их обсуждений. В результате исследования было выявлено, что категории и частота вопросов, рассматриваемых на заседаниях Комиссии, не всегда имеют прямую связь с зафиксированными в официальных службах трудовыми нарушениями. При этом количество трудовых нарушений по категориям вопросов сокращается в связи с установлением согла-
\end{abstract}


сованности между тремя сторонами, что подтверждает значимость установления социального диалога между его участниками. Кроме того, автором были определены основные проблемы в работе Российской трехсторонней комиссии на основе изученных протоколов.

Ключевые слова: социальный диалог, Российская трехсторонняя комиссия, нарушения, социальнотрудовые отношения, объединения работников, объединения работодателей, социальные партнеры.

Термин «социальное партнерство» в России может определяться двояко в зависимости от того, какой статус имеет сторона производственных отношений: наемный работник или предприниматель, но несмотря на различное понимание, основной направленностью социального партнерства признается извлечение преимуществ для совершенствования бизнеса. Первая составляющая понятия относится к социально-трудовой сфере и связанным с ней отношениям между работниками, работодателями и государством. Согласно второй позиции, социальное партнерство представляет собой общую деятельность между некоммерческими организациями и бизнесом, государством и бизнесом или трех сторон вместе, в результате которой в итоге должна быть получена определенная социальная выгода для общества.

В рамках нашего исследования мы делаем различие между понятиями «социальный диалог» и «социальное партнерство». Во-первых, термин «социальный диалог» мы не смешиваем с понятием «корпоративная социальная ответственность». Социальная ответственность бизнеса является самостоятельным инструментом поддержки общества через конкретные совместные социальные проекты и не ставит одной из своих основных задач урегулирование вопросов, связанных с социально-трудовой сферой. Во-вторых, понятие «социальный диалог» более широкое, чем «социальное партнерство», если воспринимать его в контексте трудовых отношений, поскольку в основу формирования принципов социального партнерства были заложены практики формирования социального диалога в развитых европейских странах. Социальный диалог является одним из самых эффективных инструментов развития производственных отношений в развитых странах. Несмотря на специфические особенности государств и небольшие различия в построении и функционировании данного механизма (социального диалога), он имеет четкую направленность и свою концепцию, заложенную Международной организацией труда, использующей социальный диалог в качестве основы построения социально-трудовых отношений [7].

Стоит также отметить, что термин «социальный диалог» является научным понятием и используется в основном для описания результатов исследования. В повседневности данное понятие редко озвучивается и подменяется различными категориями вопросов, такими как забастовочная деятельность, профсоюзное движение, благотворительность бизнес-структур, социальный проект, меценатство и другими. Кроме того, говоря о принципах реализации социального диалога в России, в первую очередь, возникают образы из советского прошлого: поддержка рабочих профсоюзами, общая собственность, полная передача ответственности за благополучие в обществе государству (властным структурам). Однако основной идеей реализации социального диалога является его направленность на солидарную ответственность, доверительные отношения между сторонами, работа ради общего дела (повышения производительности предприятия) и получения выгод каждой стороной. Это связано прежде всего с недостаточной подготовленностью российской экономики в целом к внедрению механизма без потери его ключевых особенностей, делающих его одним из самых эффективных инструментов развития социально-трудовых отношений в европейских странах. Так, А.И. Казачева, отмечая широкое применение социального диалога в европейских странах, указывает на его статус, не только как узаконенного государством института, но и определенного особенностями и традициями развития стран [1].

Применительно к российской действительности хотелось бы согласиться с автором статьи «Социальное партнерство в России: есть ли предпосылки?» Э.Н. Соболевым, который утверждает, что попытки устройства социального диалога по примеру европейских 
стран в 90-е годы были безуспешными ввиду неготовности субъектов социально-трудовых отношений к социальному диалогу: государство не служило гарантом соблюдения прав работников и работодателей, профсоюзам не хватало навыков эффективного ведения переговоров, а работодатели были сосредоточены в основном на контрактах с государством, что противоречило идее реализации социального диалога по европейским шаблонам [6].

Однако, обращаясь к статье С. Николаева, отметим, что социальный диалог способен оказывать влияние на формирование и реализацию социальной политики государства, поскольку развитие партнерских отношений между субъектами трудовой сферы обусловлено самой природой российской государственности и способствует положительному воздействию на идеологическое состояние современного общества [2].

В целях исследования социального диалога в России нами был проведен анализ работы Российской трехсторонней комиссии, представляющей социальный диалог на российском рынке труда на национальном уровне. Российская трехсторонняя комиссия (далее - Комиссия) является федеральным координационным органом, согласующим интересы объединений работников, объединений работодателей и Правительства РФ. Деятельность комиссии регламентируется Федеральным законом «О Российской трехсторонней комиссии по регулированию социально-трудовых отношений» от 01 мая 1999 г. № 92-Ф3 и Трудовым кодексом РФ (часть II, раздел II «Социальное партнерство в сфере труда») [3].

Данный уровень реализации принципов социального диалога был исследован с целью определения тесноты связи между рассматриваемыми вопросами на федеральном уровне и официально зарегистрированными обращениями по трудовым спорам, что немаловажно для дальнейшего анализа результативности деятельности Комиссии для других уровней социально-трудовых отношений [5].

В качестве материалов исследования были проанализированы протоколы заседаний Комиссии за последние 8 лет (2010-2017 гг.). Каждый год комиссия проводит не более 11 заседаний. В таблице 1 представлены данные с укрупненными категориями вопросов, рассматриваемых на заседаниях РТК, а также выявлены по каждому разделу согласованные и несогласованные вопросы. При этом в число несогласованных вопросов входит как полное отсутствие согласия, так и частичное согласие с учетом дальнейших доработок однако, мы в исследовании относим подобное решение к несогласованности интересов трехстороннего сотрудничества.

Наиболее часто повторяющиеся вопросы заседаний связаны с бюджетами Фонда медицинского страхования, Пенсионного фонда, Фонда социального страхования, а также проблемами пенсионного, медицинского и социального страхования, что вполне логично, поскольку данные вопросы за рассматриваемый период закреплены в Генеральном соглашении и обязательны для обсуждения тремя сторонами Комиссии. Вопросы реализации Генерального соглашения также являются прямой непосредственной функцией Комиссии. По остальным трудовым вопросам наибольшее количество обращений было зафиксировано по следующим категориям: компенсации при несчастных случаях и профессиональных заболеваниях, специальная оценка условий труда, пенсионная реформа, иностранные работники, оплата труда различных категорий профессий, оценка квалификации, аттестация, развитие программ повышения квалификации.

Наибольшего согласия стороны Комиссии достигали по вопросам, связанным с профессиональными стандартами, соблюдения законодательства, охраны труда, морским и внутренним водным транспортом (более 75 \% положительных результатов переговоров).

Абсолютного несогласия стороны достигли по вопросам бюджетной и налоговой политики, социальной защиты инвалидов, а также увольнения работников.

Среди вопросов, попавших в категорию «Разное», были сферы, к которым обращались на заседаниях менее трех раз за весь исследуемый период, среди них следующие:

1) валютное регулирование;

2) государственные программы;

3) государственная служба;

4) защита прав юридических лиц и ИП;

5) индексация выплат,

6) лицензирование видов деятельности,

7) микропредприятия; 
К.А. Субхангулова. Деятельность Российской трехсторонней комиссии

8) мобильность трудовых ресурсов;

9) неполный рабочий день;

10) нормирование рабочего дня;

11) оплачиваемый отпуск;

12) основные направления деятельности на рынке труда 2011-2015 гг.;

13) подземные работы;

14) популяризация инженерных профессий;

15) пособия по беременности, уходу за детьми, а также уходу за детьми-инвалидами;

16) служебные командировки;

17) справочник профессий;

18) среднее и малое предпринимательство;
19) территории опережающего социально-экономического развития;

20) труд несовершеннолетних;

21) трудовые книжки;

22) физическая культура и спорт;

23) трудовой договор.

Таким образом, мы определили основные вопросы заседаний Комиссии, а также степени согласованности по категориям тем. В рамках данной работы мы выдвигаем следующие гипотезы:

Гипотеза 1: «Категории и частота вопросов, рассматриваемых на заседани-

Заседания РТК в период с 2010 по 2017 годы *

Таблица 1

\begin{tabular}{|c|c|c|c|c|c|c|c|c|c|c|c|c|c|}
\hline \multirow[b]{2}{*}{ Раздел } & \multirow[b]{2}{*}{ Кате гории вопросов } & \multicolumn{3}{|c|}{ Государство } & \multicolumn{3}{|c|}{ Работники } & \multicolumn{3}{|c|}{ Работодате ли } & \multirow{2}{*}{$\begin{array}{c}\text { Кол-во } \\
\text { обращений } \\
\end{array}$} & \multirow{2}{*}{$\begin{array}{c}\text { Полное } \\
\text { согласие (в } \\
\text { абс. } \\
\text { единицах) } \\
\end{array}$} & \multirow{2}{*}{$\begin{array}{c}\text { Согласие в } \\
\text { \% к } \\
\text { общему } \\
\text { числу } \\
\end{array}$} \\
\hline & & c & $\mathbf{H}$ & д & c & $\mathbf{H}$ & д & c & $\mathbf{H}$ & д & & & \\
\hline 1 & поддержка безработных & 10 & 0 & 0 & 4 & 4 & 2 & 8 & 1 & 1 & 10 & 4 & 40 \\
\hline 2 & $\begin{array}{l}\text { реализация Генерального } \\
\text { Соглашения }\end{array}$ & 8 & 0 & 4 & 7 & 0 & 5 & 7 & 0 & 5 & 12 & 7 & 58 \\
\hline 3 & образование & 3 & 0 & 0 & 2 & 0 & 1 & 1 & 1 & 1 & 3 & 1 & 33 \\
\hline 4 & помощь жителям Крайнего Севера & 4 & 0 & 1 & 4 & 0 & 1 & 4 & 0 & 1 & 5 & 4 & 80 \\
\hline 5 & профессиональные стандарты & 7 & 0 & 0 & 7 & 0 & 0 & 7 & 0 & 0 & 7 & 7 & 100 \\
\hline 6 & бюджет Пенсионного фонда & 12 & 0 & 3 & 9 & 1 & 5 & 8 & 2 & 5 & 15 & 8 & 53 \\
\hline 7 & $\begin{array}{l}\text { бюджет Фонда медицинского } \\
\text { страхования }\end{array}$ & 15 & 0 & 2 & 10 & 1 & 6 & 10 & 1 & 6 & 17 & 10 & 59 \\
\hline 8 & $\begin{array}{l}\text { бюджет Фонда социального } \\
\text { страхования }\end{array}$ & 12 & 0 & 3 & 8 & 0 & 7 & 8 & 0 & 7 & 15 & 8 & 53 \\
\hline 9 & $\begin{array}{l}\text { компенсации при несчастных } \\
\text { случаях и профессиональных } \\
\text { заболеваниях, специальная оценка } \\
\text { условий труда, охрана труда }\end{array}$ & 19 & 2 & 5 & 17 & 3 & 6 & 16 & 4 & 6 & 26 & 16 & 62 \\
\hline 10 & занятость населения & 9 & 0 & 0 & 6 & 1 & 2 & 6 & 1 & 2 & 9 & 6 & 67 \\
\hline 11 & иностранные работники & 14 & 0 & 1 & 8 & 3 & 4 & 12 & 1 & 2 & 15 & 8 & 53 \\
\hline 12 & $\begin{array}{l}\text { оплата труда различных категорий } \\
\text { профессий }\end{array}$ & 13 & 0 & 1 & 9 & 2 & 3 & 10 & 1 & 3 & 14 & 8 & 57 \\
\hline 13 & $\begin{array}{l}\text { оценка квалификации, аттестация, } \\
\text { развигие ППК }\end{array}$ & 12 & 0 & 1 & 9 & 0 & 4 & 9 & 0 & 4 & 13 & 9 & 69 \\
\hline 14 & MPOT & 6 & 0 & 0 & 3 & 1 & 2 & 2 & 1 & 3 & 6 & 2 & 33 \\
\hline 15 & соблюдение законодательства & 4 & 0 & 0 & 4 & 0 & 0 & 4 & 0 & 0 & 4 & 4 & 100 \\
\hline 16 & социальное обеспечение & 5 & 0 & 1 & 4 & 1 & 1 & 4 & 0 & 2 & 6 & 4 & 67 \\
\hline 17 & $\begin{array}{l}\text { пенсионное,медицинское, социальное } \\
\text { страхование }\end{array}$ & 24 & 0 & 3 & 15 & 6 & 6 & 13 & 4 & 10 & 27 & 13 & 48 \\
\hline 18 & пенсионная реформа & 17 & 0 & 1 & 6 & 7 & 5 & 6 & 0 & 12 & 18 & 6 & 33 \\
\hline 19 & деятельность РТК & 12 & 1 & 1 & 10 & 2 & 2 & 11 & 1 & 2 & 14 & 9 & 64 \\
\hline 20 & праздники, выходные & 13 & 0 & 0 & 12 & 1 & 0 & 12 & 1 & 0 & 13 & 12 & 92 \\
\hline 21 & $\begin{array}{l}\text { морской и внутренний водный } \\
\text { транспорт }\end{array}$ & 4 & 0 & 0 & 3 & 1 & 0 & 4 & 0 & 0 & 4 & 3 & 75 \\
\hline 22 & бюджетная и налоговая политика & 7 & 0 & 0 & 0 & 0 & 7 & 0 & 0 & 7 & 7 & 0 & 0 \\
\hline 23 & социальная защита инвалидов & 2 & 0 & 1 & 1 & 0 & 2 & 0 & 1 & 2 & 3 & 0 & 0 \\
\hline 24 & увольнение работников & 2 & 1 & 0 & 0 & 3 & 0 & 0 & 2 & 1 & 3 & 0 & 0 \\
\hline 25 & разное & 27 & 1 & 4 & 20 & 3 & 9 & 19 & 2 & 11 & 32 & 18 & 56 \\
\hline
\end{tabular}

Примечание. * - («с»- согласие трех сторон, «н»- несогласие стороны, «д»-доработка).

Составлено автором на основе протоколов Комиссии, представленных на сайте Правительства РФ [5]. 


\section{ЭКОНОМИЧЕСКАЯ ТЕОРИЯ}

ях Комиссии, имеет прямую связь с трудовыми нарушениями».

Гипотеза 2: «Количество трудовых нарушений по категориям вопросов сокращается в связи с установлением согласованности между тремя сторонами».

Для этого рассмотрим, какие нарушения были выявлены по итогам работы государственных инспекций труда в субъектах Российской Федерации за 2013-2016 гг, представленных в отчетах Федеральной службы по труду и занятости [4]. Рассмотреть временной промежуток (2010-2017 гг.), аналогичный периоду исследования работы Ко- миссии, не удалось, поскольку в открытых источниках информация предоставлена только за 4 года.

В результате, получаем диаграмму (рис. 1), где отчетливо прослеживается наибольшее количество обращений по нарушениям в рамках социально-трудовой сферы по четырем вопросам, касающимся:

1) трудового договора;

2) оплаты и нормирования труда;

3) обучения работников по охране труда;

4) охраны труда.

Однако с 2013 по 2016 гг. наблюдается в целом сокращение количества выявленных

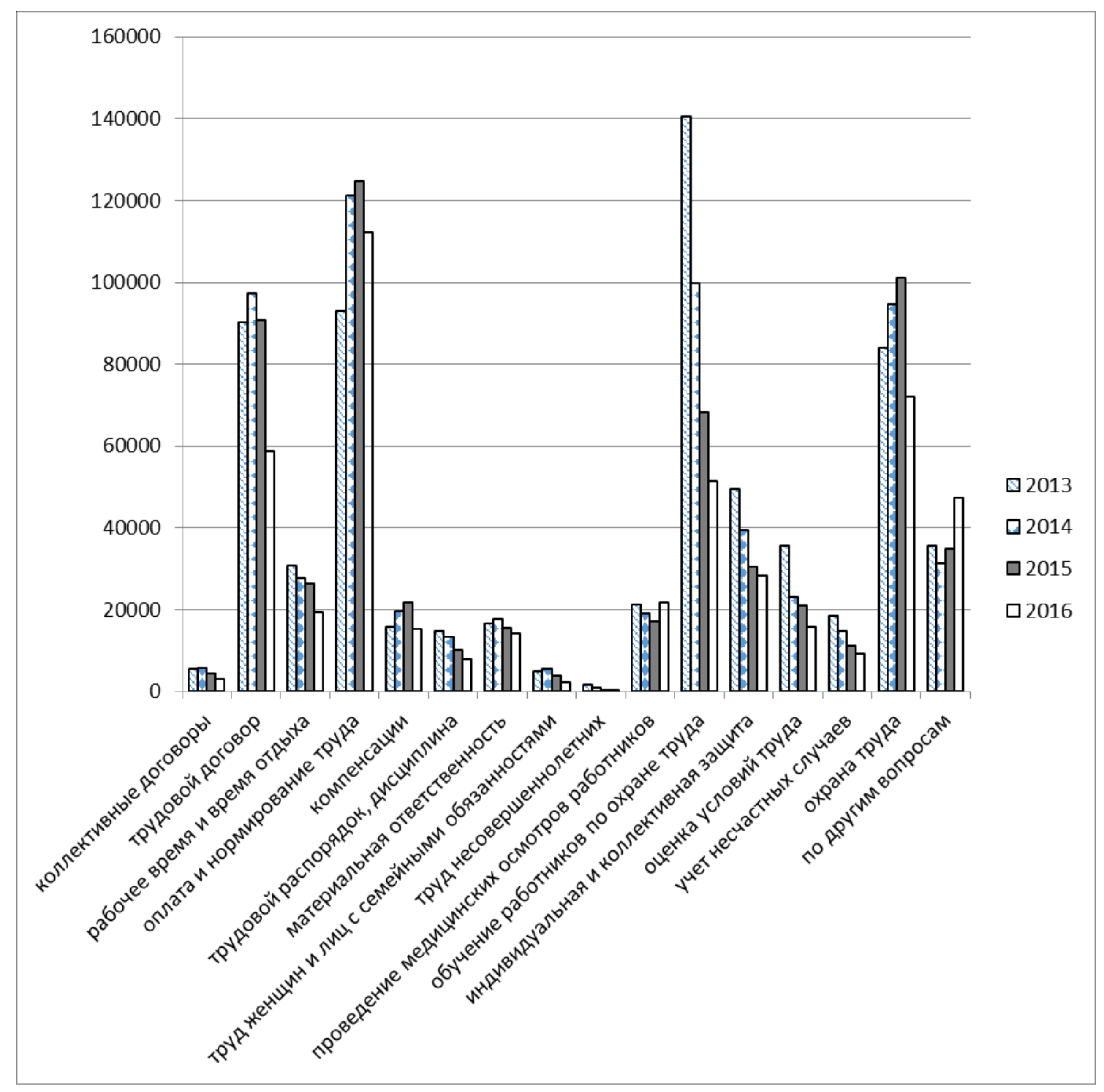

Рис. 1. Выявленные нарушения по категориям вопросов

Примечание. Составлено по данным о количестве трудовых нарушений отчетов о работе государственных инспекций труда в субъектах Российской Федерации за 2014, 2015, 2016 гг. [4]. 
нарушений по категориям вопросов [4]. Исключения составляют лишь некоторые вопросы: за 4 года количество нарушений либо не сократилось, либо выросло. Так, например, вопрос оплаты и нормирования труда - в 2014 и 2015 гг. количество нарушений с каждым годом увеличивалось, а к 2016 упало, однако осталось высоким по сравнению с уровнем 2013 г. (выше на $21 \%$ ).

Таким образом, наша гипотеза 1 оправдалась частично. Так, вопросы, связанные с трудовым договором, не так часто поднимаются в рамках трехсторонних обсуждений на федеральном уровне, они попали в категорию «Разное», предполагающую, что данный вопрос (в чистом виде) был рассмотрен не более 3 раз за 8 лет, в то время как количество выявленных нарушений по данному вопросу было одним из наибольших (что не подтверждает гипотезу 1). В то же время проблема оплаты и нормирования труда являлась одной из самых актуальных на заседаниях Комиссии, что может являться откликом на зафиксированное огромное количество нарушений в данной области (подтверждает гипотезу 1). Рассмотрим количество обращений к данному вопросу за 2013-2016 гг. (рис. 2).

Таким образом, частота рассмотрения проблем, связанных с оплатой и нормированием труда, на заседаниях Комиссии имеет прямую связь с количеством правонарушений по данной категории вопросов, выявленных государственной инспекцией труда. Наибольшее количество рассмотрений данного вопроса относится к 2014 г. (5 раз поднимался на заседаниях Комиссии), при этом как мы видим абсолютного согласия между собой стороны трехсторонних переговоров не достигли. И это подтверждает гипотезу 2: полное согласие на всех заседаниях 2013-2015 гг. не достигнуто, и количество трудовых нарушений заметно не сокращается. А в 2016 г. мы видим достижение полной согласованности в данном вопросе и снижение уровня трудовых нарушений по данному разделу (см. рис. 1).

Следующие два крупных раздела, свидетельствующих о нарушениях в области охраны труда и обучения работников охране труда, мы объединили в один (см. рис. 3) и соотнесли с разделом 9 «Компенсации при несчастных случаях и профессиональных заболеваниях, специальная оценка условий труда, охрана труда» в соответствии с таблицей, составленной на основе протоколов заседаний Комиссии.

В данном случае соотнесение количества нарушений по данному вопросу и частоты обращений к вопросу на заседаниях Комиссии подтверждает гипотезу 1: за 8 лет к данному разделу Комиссия обращалась 26 раз на заседаниях и количество обращений ввиду трудовых нарушений наибольшее. Для проверки гипотезы 2 рассмотрим данный вопрос в разрезе 2013-2016 гг. (см. рис. 4).

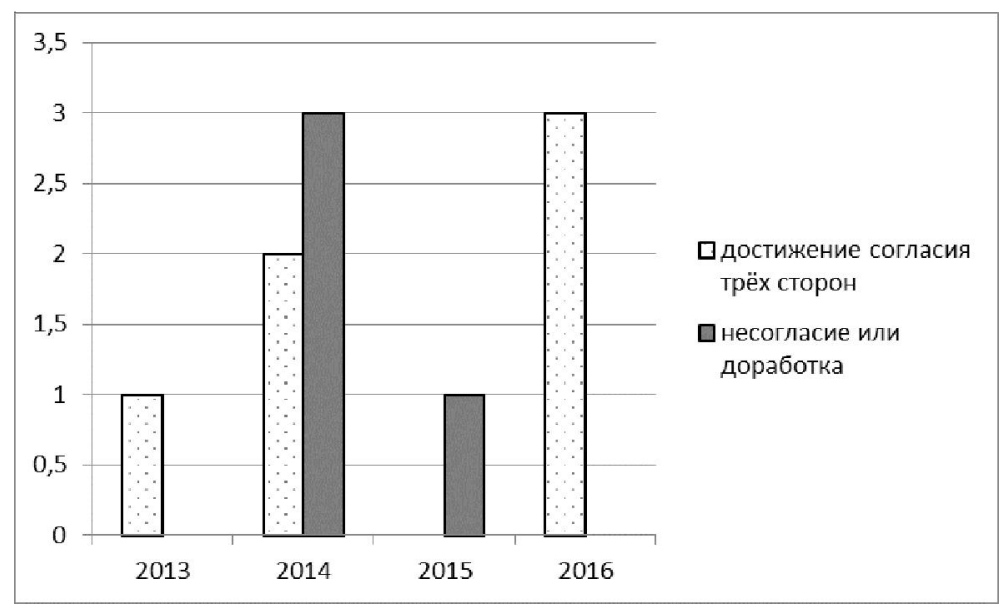

Рис. 2. Частота рассмотрения вопроса оплаты труда различных категорий работников и достижение согласованности между тремя сторонами

Примечание. Составлено автором на основе протоколов Комиссии, представленных на сайте Правительства РФ [5]. 


\section{ЭКОНОМИЧЕСКАЯ ТЕОРИЯ}

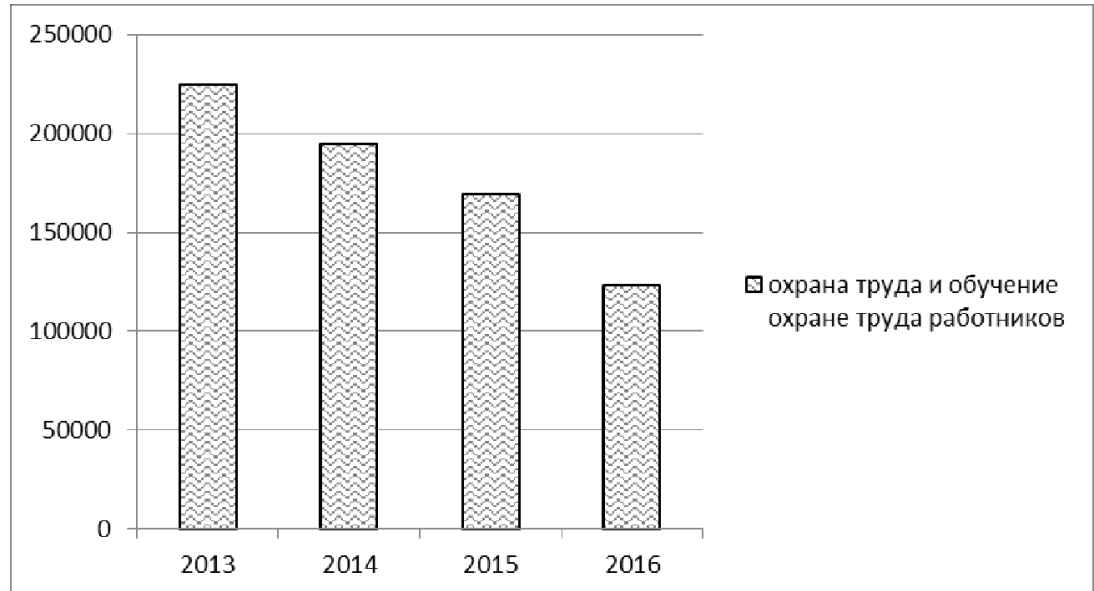

Рис. 3. Нарушения в области охраны труда и обучения охране труда работников

Примечание. Составлено автором на основе протоколов Комиссии, представленных на сайте Правительства РФ [5].

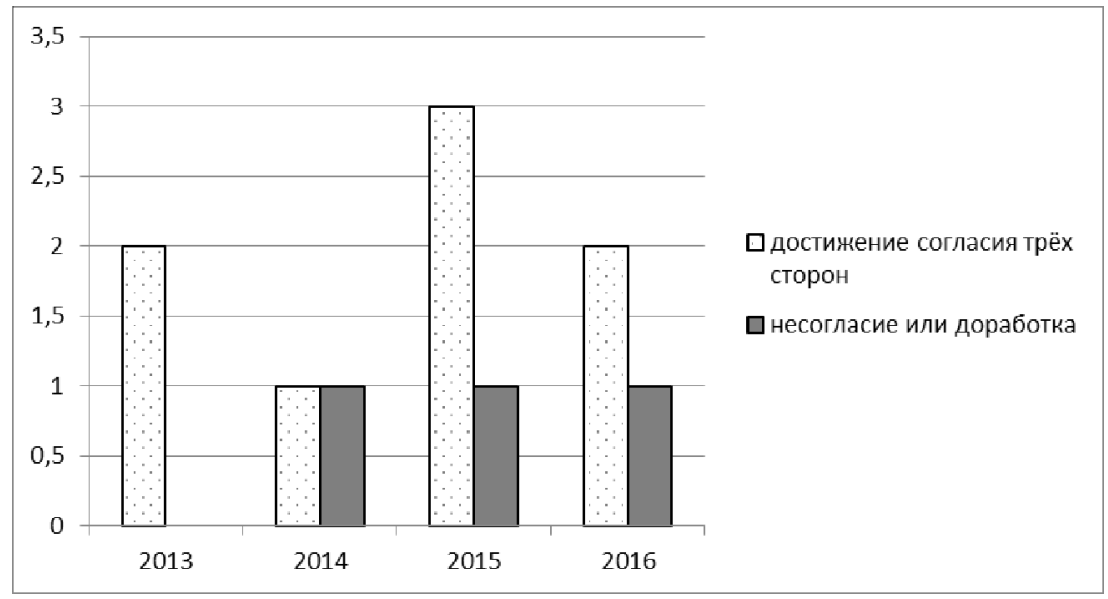

Рис. 4. Частота рассмотрения вопроса охраны труда и специальной оценки условий труда и достижение согласованности между тремя сторонами

Примечание. Составлено автором на основе протоколов Комиссии, представленных на сайте Правительства РФ [5].

Из графика видно, что частота обращений к вопросу охраны труда была постоянной в 2013 и 2014 гг., выросла в 2015 до 4 раз и снизилась до 3 раз, превысив при этом количество рассмотрений вопроса в 2013 и 2014 годах.

Кроме того на заседаниях Комиссии достигалось в основном согласие, что коррелирует с сокращением количества нарушений в области охраны труда, что подтверждает гипотезу 2 по данному разделу.

Таким образом, на наш взгляд гипотеза 1 частично подтвердилась, и категории, и частота вопросов, рассматриваемых Комис- сией, отчасти зависит от количества нарушений, выявленных государственной инспекцией труда. Однако, хотелось бы отметить, что по некоторым вопросам не всегда количество нарушений значительно сокращалось, что связано с серьезными изменениями в некоторых сферах социально-трудового взаимодействия. Поэтому Комиссия, как орган, представляющий трехстороннее сотрудничество на федеральном уровне, обязан быть одной из главных сил, направляющих изменения в правильное русло. Так, например, насущной проблемой долгих десятилетий является вопрос пенсионной реформы. На за- 
седаниях он рассматривался 18 раз, и только в $33 \%$ случаев было достигнуто согласие сторон, что говорит о разобщенности интересов государства, объединений работников и работодателей.

Гипотеза 2, на наш взгляд, подтвердилась, количество трудовых нарушений по категориям вопросов сокращается в связи с установлением согласованности между тремя сторонами. Что подтверждает значимость установления социального диалога между его участниками.

Также проанализировав информацию о проведенных заседаниях Комиссии за последние 8 лет, были выявлены следующие проблемные зоны в работе:

- часто не учитываются мнения объединений работников и работодателей при принятии нормативно-правовых актов, Правительство единолично рассматривает многие законопроекты;

- государство, являясь также работодателем, чаще действует в тандеме с объединениями работодателей, что прослеживается при исследовании принятых решений в протоколах Комиссии;

- слабая законодательная база в части мониторинга процессов осуществления принятых решений и игнорирование части принятых решений, - данная проблема была подчеркнута в рамках заседаний Комиссии, которая ищет способы разрешения ситуации;

- нарушение исполнения Генерального соглашения, а также процедуры ведения переговоров.

Таким образом, мы выявили основные недостатки деятельности РТК, а также основные вопросы в 2010-2017 гг., на которые было выделено наибольшее количество рассмотрений на заседаниях Комиссии. На заседаниях обсуждаются преимущественно вопросы, связанные со страхованием, планированием бюджетов Пенсионного фонда, Фонда медицинского страхования и Фонда социального страхования (что обусловлено выполнением обязательств Генерального соглашения между сторонами), охраной труда, несчастными случаями, трудовой деятельностью иностранных лиц, пенсионной реформой, оплатой труда и образованием. При этом, как мы выявили, комиссия не уделяет должного внимания проблемам, возникающим по причинам нарушения трудовых договоров, а именно последние составляют одну из наибольших категорий нарушений в социально-трудовых отношениях по данным государственной инспекции труда.

\section{СПИСОК ЛИТЕРАТУРЫ}

1. Казачева, А. И. Социальный диалог как форма развития социально-трудовых отношений / А. И. Казачева // Омский научный вестник. -2011 . № 2 (96). - Электрон. текстовые дан. - Режим доступа: https://cyberleninka.ru/article/n/sotsialnyydialog-kak-forma-razvitiya-sotsialno-trudovyhotnosheniy (дата обращения: 05.03.2018). - Загл. с экрана.

2. Николаев, С. Социальное партнерство способствует развитию современного российского общества / С. Николаев // Социальное партнерство. М. : Изд-во ООО «ОЙЛ ПРЕСС», 2012. - № 2 (53). 97 c. - Электрон. текстовые дан. - Режим доступа: http: //www.oilru.com/pdf_sp/social_partnership_35.pdf(дата обращения: 02.03.2018). - Загл. с экрана.

3. О Российской трехсторонней комиссии по регулированию социально-трудовых отношений : федер. закон от 01 мая 1999 г. № 92-ФЗ (в ред. Ф3 от 23 мая 2016 г. № 142-Ф3; от 28 дек. 2016 г. № 511-Ф3) принят Государственной думой 2 апр. 1999 г. - Доступ из справ.-правовой системы «КонсультантПлюс».

4. Отчеты о работе государственных инспекций труда // Официальный сайт Федеральной службы по труду и занятости. - Электрон. текстовые дан. Режим доступа: https://www.rostrud.ru/control/ soblyudenie-zakonodatelstva-o-trude/?CAT ID $=4185$ (дата обращения: 10.01.2018). - Загл. с экрана.

5. Российская трехсторонняя комиссия по регулированию социально-трудовых отношений // Официальный сайт Правительства России. - Электрон. текстовые дан. - Режим доступа: http:// government.ru/department/141/events/ (дата обращения: 02.03.2018). - Загл. с экрана.

6. Соболев, Э. Н. Социальное партнерство в России: есть ли предпосылки? / Э. Н. Соболев // Россия путь к социальному государству : материалы Всерос. научной конференции. - М. : Изд-во Научный эксперт, 2008. - С. 562-576.

7. Социальное партнерство в России. Сборник лучших практик // Информационно-аналитический журнал «Бизнес\&общество». - М., 2015. 74 c. - Электрон. текстовые дан. - Режим доступа: http://asp.org.ru/wp-content/uploads/2017/03/ sotsialnoe-partnerstvo-v-rossii.pdf (дата обращения: 03.03.2018). - Загл. с экрана. 


\section{REFERENCES}

1. Kazacheva A.I. Sotsialnyy dialog kak forma razvitiya sotsialno-trudovykh otnosheniy [Social Dialogue as a Form of Social and Labour Relations Development]. Omskiy nauchnyy vestnik, 2011, no. 2 (96). URL: https://cyberleninka.ru/article/n/sotsialnyydialog-kak-forma-razvitiya-sotsialno-trudovyhotnosheniy. (accessed 5 March 2018)

2. Nikolaev S. Sotsialnoe partnerstvo sposobstvuet razvitiyu sovremennogo rossiyskogo obshchestva [Social Partnership Promotes the Development of Modern Russian Society]. Sotsialnoe partnerstvo [Social Partnership]. Moscow, OYL PRESS, 2012, no. 2 (53). 97 p. URL: http:// www.oilru.com/pdf sp/social partnership 35.pdf. (accessed 2 March 2018)

3. O Rossiyskoy trekhstoronney komissii po regulirovaniyu sotsialno-trudovykh otnosheniy: feder. zakon ot 01 maya 1999 g. № 92-FZ (v red. FZ ot 23 maya 2016 g. № 142-FZ; ot 28 dek. 2016 g. № 511-FZ). Prinyat Gosudarstvennoy dumoy 2 apr. 1999 g. [Federal Law 'On the Russian Tripartite Commission on Regulation Social and Labour Relations' of May 1, 1999 no. 92-FL (ed. of FL of May 23, 2016 No. 142-FL; of December 28, 2016 No. 511-FL). Adopted by the State Duma on April 2, 1999]. Access from Reference Legal System 'KonsultantPlyus'
4. Otchety o rabote gosudarstvennykh inspektsiy truda [Reports on the Work of State Labor Inspectorates]. Ofitsialnyy sayt Federalnoy sluzhby po trudu $i$ zanyatosti [Official Website of the Federal Service for Labour and Employment]. URL: https:// www.rostrud.ru/control/soblyudenie-zakonodatelstvao-trude/?CAT_ID=4185. (accessed 10 January 2018)

5. Rossiyskaya trekhstoronnyaya komissiya po regulirovaniyu sotsialno-trudovykh otnosheniy [Russian Tripartite Commission for the Regulation of Social and Labour Relations]. Ofitsialnyy sayt Pravitelstva Rossii [Official Website of the Government of Russia]. URL: http://government.ru/ department/141/events/ (accessed 2 March 2018)

6. Sobolev E.N. Sotsialnoe partnerstvo v Rossii: est li predposylki? [Social Partnership in Russia: Are There Any Prerequisites?]. Rossiya: put k sotsialnomu gosudarstvu: materialy Vseros. nauchnoy konferentsii [Russia's Way to the Social State. Proceedings of the All-Russian Scientific Conference]. Moscow, Nauchnyy ekspert Publ., 2008. 1008 p.

7. Sotsialnoe partnerstvo v Rossii. Sbornik luchshikh praktik [Social Partnership in Russia. Best Practices]. Informatsionno-analiticheskiy zhurnal «Biznes\&obshchestvo» [Business\&Society]. Moscow, 2015. 74 p. URL: http://asp.org.ru/wpcontent/uploads/2017/03/sotsialnoe-partnerstvo-vrossii.pdf. (accessed 3 March 2018)

\section{Information about the Author}

Kseniya A. Subkhangulova, Postgraduate Student, Faculty of Economics, Lomonosov Moscow State University, Leninskie gory St., 1, 119991 Moscow, Russian Federation, xyundra@mail.ru.

\section{Информация об авторе}

Ксения Альмировна Субхангулова, аспирант экономического факультета, Московский государственный университет им. М.В. Ломоносова, Ленинские горы, 1, 119991 г. Москва, Российская Федерация, хуundra@mail.ru. 